\title{
Effect of Parboiling Technique on the Nutritional Quality of Rice
}

\author{
Niyonshima Alexandre ${ }^{1,2 *}$, Hategekimana Jean Paul ${ }^{1}$ and Nyirahanganyamunsi Gerardine ${ }^{1}$ \\ ${ }^{1}$ Department of post-harvest management, Rwanda Agriculture and Animal resources Development Board (RAB), Rwanda
}

${ }^{2}$ Department of Food Science and technology, University of Rwanda, Rwanda

*Corresponding author: Niyonshima Alexandre, Department of Post-harvest Management Program, Rwanda Agriculture and Animal Resources Development Board (RAB) and Department of food science and technology, CAVM, University of Rwanda (UR), Rwanda.
Received Date: February 03, 2020

Published Date: June 10, 2020

\begin{abstract}
Rice (Oryza sativa) is among the seven crops of priorities in Rwanda that play a role in food security within household. Different varieties of rice both short and long are grown in Rwanda, among them Zong zeng, Yune Eritian and XY are grown and consumed in almost all parts of the country. The same for other crops, a huge amount of rice produced is lost during handling activities before reaching the consumer. The loss includes breakage, and loss of nutrients due to the removal of bran and husk. Different techniques are used for the reduction of such post-harvest losses of rice and rice parboiling is among the most useful techniques applied to reduce postharvest losses of rice and is now applied in different parts of the world. However, this technique has not yet been adopted by Rwandans for prevention of loss of rice after harvesting. Therefore, the objective of the present study was to assess the effects of parboiling technique on physico-chemical parameters of different rice varieties grown in Rwanda and to do its awareness for Rwandan population. Three new varieties: Zong Zeng, Yune Eritian, and XY were further prepared and analysed in comparing with the same rice varieties that is not parboiled. Paddy was weighed, cleaned 3 times, pre-steamed, soaked in water of $800 \mathrm{C}$ at ratio of 1: $2.5 \mathrm{in}$ water bath set at $800 \mathrm{C}$ for 4 and 6 hours, and then the steaming was done for $10 \mathrm{~min}$ at $100 \mathrm{OC}$. Drying followed in order to reduce the moisture content using the dryer set at $\left(20-25^{\circ} \mathrm{C}\right)$ and the the final moisture content was $13 \%$. Dried rice was then milled in a mortar by use of a pestle to remove husks. Nutritional analysis was done by measuring Ash, protein, fat and Vitamin B1. The findings of the present study show that parboiling resulted in increase of Fat, Vitamin B1, Protein and Ash content. 4 hours soaking time showed effect on the acceptability as the rice soaked for 4 hours has been more accepted compared to the one soaked for 6 hours. 6 hours soaking time resulted in considerable increase of B1 compared to other used soaking times. Therefore, we can conclude that parboiling method is a good method for reduction of rice lost during rice processors and fighting against diseases such as beriberi caused by deficiency of Vitamin B1 due to its associated increase in B1.
\end{abstract}

Keywords: Zong Zeng; Yune Eritian; XY parboiling; Steaming; Vitamin B1.

Abbrevations: ANOVA: Analysis of Variance; CAVM: College of Agriculture, Animal Sciences and Veterinary Medicine; FAO: Food Agricultural Organization; G: Grams; MINAGRI: Ministry of Agriculture and Animal Resources; MINICOM: Ministry of Trade and Industry; MT: Metric Tones; NISR: National Institute of Statistics Rwanda; \%: percentage; RCA: Rwanda Cooperative Agency; RDB: Rwanda Development Board; UR: University of Rwanda; YE: Yune Eritian; ZZ: Zong Zeng

\section{Introduction}

\section{Background}

Rwanda has a surface area of $26338 \mathrm{~km} 2$ and the population in 2012 the total resident population was 10,515,973 inhabitants (NISR, 2014). Rwanda is a mountainous country with high land and flooded valley. As a result, the temperatures are generally low. An nual average temperatures range from 15 to 25 degree centigrade. Temperatures are much lower in lowlands producing areas. Rwanda has also about 165000 ha of marshes of which 66000 ha can be developed into rice fields, currently about 12000 ha are irrigated. Rice is almost exclusively grown in marshlands at an altitude of 800 to $1200 \mathrm{~m}$ above the mean sea levels over two seasons; wet season 
(A) (March-August) and dry season (B) (September-January) (A Kathiresan, 2013).

Rice is a cereal crop from poaceae (graminiae) family with a scientific name of Oryza sativa, rice is categorized into two categories which Japonica (short and bold type) and Indica (long type). Rice was introduced in Rwanda in 1950s through various missions from China and Korea. After the initial success of growing rice in the valleys near Kigali and in the Southern province, a number of varieties became popular in 1960s. These varieties collectively referred to as Kigoli, are of short and bold type. In Bugarama, government introduced rice varieties from India such as Basmati 370 in 1980s (A Kathiresan, 2013). In 2012, the cultivation of rice covered 14,701 ha and results in the production of $81,908 \mathrm{MT}$ of rice. It was expected that in 2018, the average productivity of 5.8 tons/Ha with a maximum of 7 tons/Ha, the cultivation area of 28,500 ha will be covered (RDB, 2017).

Due to the agricultural factors such as fertile soil, favorable weather, natural water resources, and efficient manpower make Rwanda highly suitable for rice cultivation. Furthermore, rice is preferred due to its long shelf-life, ease of cooking and transportation. Today, rice is selected as priority commodities according to MINAGRI in 2004 and has become a popular choice of food in schools, homes, restaurants, and public programs in Rwanda. For human being societies in different corners of the world. The rising incomes, growing urban population, and changing lifestyles have further aggravated the demand for rice. In response to this growing trend, the Government of Rwanda has identified rice as a priority crop since 2002. The national rice policy aimed at enhancing the productivity levels and raising the standard of post-harvest processing of rice was also developed. The vision was that Rwanda will attain self- sufficiency in rice production in the next 12 years and will be well- positioned to compete local and regional market with significant improvement in quality and value. The above policies were recommended aiming to attain the objective such as enhancing the quality of rice grains through improved management practices of harvesting, drying and storage of rice grain and raise the standard of milling operation and there by improve the quality and competitiveness of locally produced rice grains (A Kathiresan, 2010).

The postharvest activities are of great importance in terms of value addition and food losses, in spite of different strategies and programs for increasing of rice production and decrease of the rice postharvest losses is still high mainly due to inappropriate postharvest handling and storage techniques. In the rice value chain, there are several constraints which can decrease the yield during the process. Some of them start at the beginning during the preparation of field. Rice parboiling is a postharvest process carried out on paddy (unhusked) rice. Parboiling has a number of advantages, including the enhancement of the quality and yield of rice at milling and the preservation of nutritional values as parboiled rice has a longer shelf life (due to the deactivation of enzymes) and, because its grains are harder, it stores better and is more resistant to insect pests. The cooking quality of parboiled rice is better in several ways: its grains stay firm, they do not stick together, and it loses less starch during cooking [1]. So, the research will focus on the postharvest losses and how it can be treated by new technology which is parboiling. For human being societies in different corners of the world including Rwanda, rice is prepared in different ways such as boiling, where rice is soaked in 3-4 quart of water for 1 quart of rice, and boil for 15-20 minutes approximately.

In Rwanda, the parboiling technique is not applied, or it affects the nutritional content and other aspects that have been indicated by many researchers such as improvement of flavor that lead the consumer preference and unbreakable of rice grains, reduction of cooking time, etc. The aim of the present study is to apply the parboiling technique for rice preparation and determine its effects on different rice varieties grown in Rwanda.

\section{Problem statement}

Rice is a staple food which has a high demand of consumption compared to its production on market, as in 2012 rice consumption compared to other crop was $6.9 \%$ where $3.8 \%$ was produced (local) and 3.1\% was imported, not only inside the country but also outside where in East Africa community the demand of rice is $\geq$ 2,088,000MT, according to RDB, 2017. Rice when milled is classified into 3types such as heady rice (long grain, medium grain, short grain), rice flour and broken rice grain; the breakage lead to post harvest loss and consumer do not prefer the quality of rice produced.

Different diseases such as beriberi and Wernicke-Korsakoff syndrome which are diseases caused by a deficiency of thiamine (vitamin B1) that affect the nervous system, cause visual impairment, lack of muscle coordination, mental decline, breathing, eye movement, heart function, alertness are caused by lack of vitamin B1 which is likely to be low in white rice as bran which is rich in Thiamine, riboflavin, niacin or nicotinic acid and mineral such as Calcium, Phosphorus, Potassium, Sodium has been removed by the milling and polishing; one of method to acquire all those nutrient is parboiling which refers to the hydrothermal treatment technique called parboiling and such rice will be a parboiled rice which will be rich in all those nutrients. The storage time or the shelf life of a product is so important, and parboiling is one of the ways of reducing the post-harvest losses of rice during storage that can be caused by rodents, insects, and other pests and increasing its storage time as the parboiled rice is very resistant to insect and rodent.

\section{Objectives}

\section{General objectives}

Reduction of post-harvest losses in quality and quantity of rice varieties grown in Rwanda by introducing and application of parboiling techniques 


\section{Specific objectives}

- $\quad$ Strengthen the physical chemical structure of rice grain toward the reduction of post-harvest losses

- $\quad$ Help the population to consume thiamine (Vitamin B1) and other nutrient that help to fight against disease such as beriberi are needed by our body

- To make a comparison on consumer acceptability between parboiled rice and non-parboiled rice

\section{Hypothesis}

- $\quad$ Parboiled rice is more nutritive than non-parboiled rice

- $\quad$ Parboiled rice is more preferred by consumer

- The nutrient content in parboiled rice differ according to variety

\section{Outcome/ Significance of the Study}

Actually the post-harvest losses is about 35\%, including loss during threshing which take place during harvesting, milling through the removal of the husk and bran yet they are rich Mineral (Calcium, Iron, Sodium, Zinc, Potassium), Lipids, Proteins, Insoluble fiber, Soluble fiber, Carbohydrates, Energy, Palmitic acid, Stearic acid, oleic acid, Linoleic acid, Linolenic acid and all these nutrient are needed by human for better growth according to S Faria [2] and A Abbas [3]. During preparation of rice such as milling brown rice is separated from husk through ventilation process and whitening stage or milling remove bran layer from brown during that preparation different nutrient are lost such as B vitamin, Iron, Thiamine at $80 \%$, Niacin, Riboflavin and Protein.

Also there is a loss during storage caused by insect, rodent and other such as temperature, water and other; therefore the project will reduce the post-harvest losses to $10 \%$ in line to increasing the production available on the market as well as consumer acceptability. With the introduction of parboiling techniques, which result in improving of the quality of rice in line with rising nutrition content and shelf life. Therefore, the information from this report based on above mentioned benefits for improvement of consumer health (fight against diseases) and reduction of postharvest losses (reduction of rice breakability during postharvest handling) of parboiling technic will be useful for rice processors, consumers, extension workers for awareness of such technic among different stakeholders and beneficiaries.

\section{Literature Review}

\section{Introduction}

Rice is number one food crop of the world. It is called ice/paddy in English, Irz in Arabic, Biranj in Persian and Chawal in Urdu language. Its botanical name is Oryza sativa. Rice cultivation started before the beginning of civilization of southern Asia and by the evidence it has seems that rice was first cultivated as a staple food crop of Asia. By the earliest records of the writings of Chinese, some 5000 years ago, it has been found out that sowing of rice was limited to the emperors only. The country from which the rice plant had its origin have not been ascertained but by the evidence available have been clear that it has got its origin from South East Asia from where it spread towards North Asia [4].

The harvested rice kernel, known as paddy, or rough, rice, is enclosed by the hull, or husk. During milling technic both the hull and bran layers of the kernel are removed, and a coating of glucose and talc is sometimes applied to give the kernel a glossy finish. Generally the classification of rice according to the layers that are removed, include Brown rice which is processed to remove only the husks and contains about 8 percent protein and small amounts of fats and is a source of thiamine, niacin, riboflavin, iron, and calcium. White rice is milled by removing the bran and is greatly diminished in nutrients. For the white rice there is a risk of beriberi if it becomes a major portion daily diet as beriberi is disease that resulting from a deficiency of thiamine and minerals. And parboiled rice is processed before milling where it is half cooked (soaked in hot water) and after it is steaming and dried and after it is milled for eating purpose this technic help to retain most of the nutrients such as mineral, B vitamin [5].

The principal rice producing countries are China, India, Japan, Bangladesh, Indonesia, Thailand, and Myanmar (Burma). Other important producers are Vietnam, Brazil, South Korea, the Philippines, and the United States. In the late 20th century the world rice crop averaged between 800 billion and 950 billion pounds annually and was cultivated on an average of about 358 million acres (145 million hectares) (Britannica, 2018)

\section{Nutrition content}

Rice seeds have element of protein, starch, oil, salt and fiber in them which are all the needs of human body. Moreover, rice also contains enough of vitamins B, E and G. Vitamins are vital elements of foods. Unfortunately, most of these vitamins are lost with the husk when milled, the fibrous cover of the rice seed. Indigenously husked rice retains some of these vitamins. However, polish removes all the vitamins from rice [6].

Rice lipids, commonly denoted as oil ('rice bran oil') due to its liquid character at room temperature, are characterized by a high nutritional value. The high proportion of unsaturated fatty acids, accounting for up to $80 \%$, causes the liquid consistency of the oil. Due to its high level of unsaturation, rice bran oil is known to have blood cholesterol lowering effects. The major unsaturated fatty acids in rice oil are oleic acid (a monounsaturated acid) and linoleic acid (an essential polyunsaturated fatty acid) (Oko AO, 2012).

Protein is the second most abundant constituent of rice [7]. Rice protein is of very high quality compared to other food crops. Rice is nutritionally superior to many other foods that are rich in carbohydrates. The protein content of the grain, although subject 
to extreme varietal and environmental variability, averages about 7 $\%$ in milled rice and $8 \%$ in brown rice [8]. The amino acid balance of rice protein is exceptionally good. Lysine content, for example, averages about 3.8 to $4.0 \%$ of the protein. Protein quality is determined by the amino acid composition and by its digestibility [9] The amino acid profile of rice shows that it is high in glutamic and aspartic acid, while lysine is the limiting amino acid [10].

Rice is a good source of insoluble fiber. Insoluble fiber reduces the risk of bowel disorders and fights constipation. Dietary fiber is highest in the bran layer (and the hull) and lowest in milled rice. The bran layer of brown rice provides valuable dietary fiber (Oko AO, 2012).

\section{Rice post-harvest losses}

The post-harvest loss of rice takes place during harvesting (1$3 \%)$, handling (2-7\%), threshing (2-6\%), drying (1-5\%), storage (2$6 \%)$, milling and transport (2-10\%) and also depend on the method used either mechanization, manually, and animals. The reduction in the moisture content of rice grain and the removal of inedible portions such as husk and bran in the process of milling are considered as post-harvest losses. Rice kernel breakage during the milling process is affected by different parameters such as paddy harvesting conditions, paddy drying, physical properties of paddy kernels, environmental conditions, and type and quality of milling system components. Environmental conditions, such as drought, low sunlight intensity, disease, inadequate or excessive nitrogen and draining water early in hot weather, all intensify stress on rice kernels. The tendency of kernels to break under stress differs somewhat among varieties [11].

Rwandan population is increasingly becoming more reliant on the market for food consumption, post-harvest handling, storage; marketing and value addition therefore are paramount/ important in ensuring that farmers receive the benefits from the increased production. Furthermore, the processing and correct storage improves the nutritional and food security status of the farmer [12]. The better milling technology should take care of the problems of impurities, lack of uniformity, and high percentage of broken grains that care will help to solve problems of taste, storability, cooking time, water absorption and other characteristics that are not apparent to the eye. Parboiling may be used to increase water absorption during cooking.

Parboiling provides a promising avenue for increasing the quality of local rice. Rice parboiling is a common practice in some sub-Saharan African countries like Cameroon, Nigeria, Ghana and Benin [13]. The parboiled rice is mainly for domestic consumption, as in Benin (Fofana et al. 2011), or for export and domestic consumption in the case of Cameroon. The main reason for parboiling rice is to reduce grain breakage during milling, although it also has been shown that the nutritional quality of parboiled rice is superior to non-parboiled rice [14]
Un milled rice contains a significant amount of dietary fiber and more nutrients than milled or polished white rice. Most rice is consumed as white polished grain despite the valuable food content of brown rice. The complete milling and polishing that converts brown rice into white rice destroys $67 \%$ of the vitamin B3, $80 \%$ of the vitamin B1, $90 \%$ of the vitamin B6, half of the manganese, half of the phosphorus, $60 \%$ of the iron, and all of the dietary fiber and essential fatty acids. These nutrients are lost when bran is removed during milling (Oko AO, 2012).

\section{Rice policy in Rwanda}

The Post-harvest losses of rice is a challenge facing the country and it is for this reason that the Government of Rwanda proposed the new policies in order to prevent and decrease the losses whereby farmers can be allowed to sell their products with profit. The new policies also proposed setting of base price for paddy for farmers and allowed the sale of paddy by farmers through a registered network of traders and/or directly to the millers. The rice growing cooperatives must have legal status registered by the Rwanda Cooperatives Agency (RCA). Paddy shall be sold by farmers only to their respective cooperatives. Thus, the new policy instructions from MINICOM banned individual rural traders (A Kathiresan, 2013).

The government has set rice production as a priority, especially in the valley bottom marshlands, which have a potential yield of 7Metric Tons/ ha. Government aims to increase in productivity to a projected national average of 7MT/ ha of unmilled rice; extend the area cultivated to about 67,000 Ha of marshland; construct and maintain water supply system to allow for two growing seasons per year; and improve handling and processing infrastructure to minimize the post-harvest loss and maximize the quality and quantity of the harvest [12]. According to the report of MINAGRI in season B in 2011 in the area of rice has made high productivity of $30 \%$ as they have improved the land consolidation, and that it was effective season preparation and good weather.

The Government of Rwanda has two major objectives regarding the rice sector. The first is to increase supplies of domestic rice to reduce dependence on rice imports. The second is part of the overall objective of assuring food security for the majority of the population [5]. Several years ago, the Government of Rwanda decided to give high priority to the production of rice in the country's marshlands, where, with adequate investment in irrigation infrastructure, the crop is capable of yielding up to $7 \mathrm{t} /$ ha during each of two growing seasons (Ministry of Agriculture and Animal Resources, 2005).

\section{Climate change}

Rice plant require growing season of 4 to 5 months during which mean temperature must average at least 70F. It is associated with tropical regions, but it is also widely grown in temperate area, in tropical humid region; most of the world's rice crop is grown between the equator and $400 \mathrm{~N}$ latitude. Rice require soil with a good surface drainage where a medium or heavy clay, clays loams, 
silt loams or fine sandy loams with slowly permeable sub soil are preferred. Rice is grown with irrigation and fields are kept flooded throughout the greater part of growing season [11]. Rice is almost exclusively grown in marshlands at an altitude of 800 to $1200 \mathrm{~m}$ above the mean sea levels over two seasons; wet (A; March-August) and dry seasons (B; September-January) (A Kathiresan. 2013).

Rice is highly sensitive to diverse environmental condition especially environmental disturbance such as drought, low temperature, high winds, flooding and hail decrease rice production (Augustin, 2010). Rwanda is a country which is characterized by four seasons per year. There is a shot wet season (September to November), a short dry season (December to February), a long wet season (March to May) and long dry season (June to August).However, with those seasons, climate can be changed over the time. Thus, this presents different challenges in the country. Some of the challenges can be erosion, several floods and droughts and also this climate

Table1: Rice varieties grown in Rwanda.

\begin{tabular}{|c|c|c|}
\hline Varieties & Rice scheme where varieties is grown & Varieties aspects \\
\hline $\begin{array}{l}\text { Zhong geng (Local } \\
\text { name is Kigoli) }\end{array}$ & $\begin{array}{c}\text { Rwamagana, Cyili, Kabuye, Nyagatare, Bugesera, } \\
\text { Mukunguri }\end{array}$ & Short grain Resistant to rice blast, sheath brown rot (pseudomonas sp.) \\
\hline Yun keng 136 & $\begin{array}{c}\text { Rwamagana, Cyili, Kabuye, Nyagatare, Bugesera, } \\
\text { Mukunguri }\end{array}$ & Short grain Resistant to rice blast, sheath brown rot (pseudomonas sp.) \\
\hline Yun yine 4 & Rwamagana & Short grain Susceptible to rice blast, sheath brown rot (pseudomonas sp.) \\
\hline Yunertian 01 & $\begin{array}{c}\text { Rwamagana, Cyili, Kabuye, Nyagatare, Bugesera, } \\
\text { Mukunguri }\end{array}$ & Short grain Resistant to rice blast, sheath brown rot (pseudomonas sp.) \\
\hline Xinum 175 & Nyagatare, Rwamagana & $\begin{array}{l}\text { Short grain Very susceptible to rice blast, sheath brown rot (pseudomonas } \\
\text { sp.) }\end{array}$ \\
\hline Fac V046 & Cyili (new release) & Short grain Resistant to rice blast, sheath brown rot (pseudomonas sp.) \\
\hline Basmati 370 & Bugarama & $\begin{array}{l}\text { Long grain, good aroma, low yield, Resistance to rice blast, sheath brown rot } \\
\text { (pseudomonas sp.) }\end{array}$ \\
\hline IRON 280 & Bugarama & Short grain Resistant to rice blast, sheath brown rot (pseudomonas sp.) \\
\hline BG 400-1 & Bugarama & $\begin{array}{l}\text { Long grain, high yield, Resistance to rice blast, sheath brown rot (pseudomo- } \\
\text { nas sp.) }\end{array}$ \\
\hline IRAT & Bugarama & $\begin{array}{l}\text { Long grain, high yield, Resistance to rice blast, sheath brown rot (Pseudomo- } \\
\text { nas sp.) }\end{array}$ \\
\hline
\end{tabular}

Source: MINAGRI, 2002

\section{Integration of research and extension on the post- harvest of rice}

Rice postharvest has many challenges. Post-harvest loss is an issue to food security, loss in farmer incomes, and inefficiency in the global food system. Important elements of the post-harvest loss challenge include: many points of intervention, multiple value chains, several technologies (a dimensionality problem in terms of the technology), and value chains entrenched in weak and poorly developed agricultural systems. Post-harvest losses are also due to agricultural systems affected by poor policy choices, as well as institutional capacity constraints, low skills, and in some cases, weaknesses in the investment and private sector business-operating climate.

When considering efforts to reduce post-harvest loss significantly in the developing countries include Rwanda, we may think change can cause desertification. Therefore, this climate change has impact on postharvest losses. This include Climatic conditions, including wind, humidity, rainfall, and temperature influence both the quantity and quality of a harvest (A Kathiresan, 2013).

\section{Rice varieties grown in Rwanda}

There are different varieties of rice that are grown in Rwanda but in the first place the Chinese varieties have been the most commonly grown for the past 30 years or more. These were introduced in 1960s and when the government of Rwanda introduced large scale production of paddy of recent, varieties such as Basmati, BG, IITA, IRON and FAC have been introduced in Rwanda and some of them on high demand due to some of their attributes which include; good grain quality, good aroma, length of grain (long preferred), tolerance to diseases and yield [12]. A summary of the varieties of rice grown in Rwanda, the rice schemes where each variety is grown, and salient aspect of the varieties are summarized in (Table 1). 


\section{Parboiled rice technology adoption}

Parboiling of rice is an ancient traditional process of India. The meaning of parboiling is that rice has been partially boiled/ cooked and it is pre-cooked in paddy form. The process consists of soaking paddy in water until it is saturated, draining the excess water and then steaming or heating the grain to gelatinize the starch and after grain is then dried. Parboiling of rice has many advantages. Such as reducing grain breakage during milling, greatly improves the vitamins and other nutrients in the polished rice grain, increases the oil in the bran, reduces proneness to insect infestation, changes the cooking and eating quality of the rice and reduces the loss of nutrients during cooking.

The process is practiced in many parts of the world such as India, Bangladesh, Pakistan, Myanmar, Malaysia, Nepal, Sri Lanka, Guinea, South Africa, Italy, Spain, Nigeria, Thailand, Switzerland, USA and France. The technology adoption indices of respondents ranged from 0.2 to 0.7 , with mean of 0.46 . An average technology adoption index of 0.46 indicates that 46 percent of the recommended technology packages were adopted by farmers, in Nigeria [16]. The survey carried out in Benin showed that $90 \%$ of women reported that the new technology significantly contributed to a reduction of rice grain breakage during milling; $20 \%$ reported that it improved the milling yield and provided good-quality rice [1].

Traditional parboiling does not lead to superior rice quality since processors are often not aware of the basic technic of parboiling, despite its simplicity (Diop, 1997). In traditional parboiling, the paddy is neither pre-cleaned nor washed before soaking. This usually results in a high level of impurities in the end product (milled rice). Soaking temperature is typically higher than $90^{\circ} \mathrm{C}$ and steaming time up to 60 minutes. That traditional parboiling condition turns the color of the end product dark, with the development of a rancid flavour in storage. During steaming the samples at the bottom receive more steam over a longer period than the samples at the top. The difference in the degree of parboiling of samples from different locations within the same steaming vessel results in high grain breakage during milling and non-uniformity in the color of traditionally parboiled milled rice. The introduction of this technology will be used by improved existing technology that will help the farmers, processors and also consumers in terms of quality, reducing postharvest losses, nutritious and generating money.

\section{Material and Methods}

\section{Sample collection}

The most popular 3 varieties, Zong Zeng, Yune Eritian, and XY were obtained from RAB and were transported to food processing and analysis laboratories of UR-CAVM, Busogo campus for sample preparation, parboiling conduction, and further nutritional analysis.

\section{Applied procedure for parboiling of rice}

Rice Parboiling is defined as a method for processing paddy which helps to improve yield quantitatively and qualitatively by reducing the breakage rate and increasing vitamin (thiamine) content, the process consists in increasing the water content of paddy grains, warming and drying them in preparation for hulling and polishing (Oko AO, 2012).

In the present study, the applied parboiling process was summarized in the following steps

- Cleaning: 500 grams of paddy was weighed by using analytical balance, winnowed for the removal of impurities and was then cleaned 3 times in tap water to remove chemicals used for preservation and other impurities;

- Pre-steaming: After cleaning, the weighed amount of paddy was pre-steamed using autoclave for $10 \mathrm{~min}$ at $100 \mathrm{0C}$, the aim of pre steaming was to increase the hardness of the parboiled rice.

- Soaking: The paddy were soaked in beaker containing water of $800 \mathrm{C}$ at ratio of 1: 2.5 and then the beaker was put in water bath set at $800 \mathrm{C}$ for 4 and 6 hours, the purpose of soaking was to allow the migration of nutrients from the husk to the germ.

- Steaming: After soaking steaming was done for $10 \mathrm{~min}$ at 100 $0 \mathrm{C}$ in autoclave, as after soaking the paddy become soft and the steaming also helped in increasing the hardness of the paddy;

- Drying: Drying was done to reduce the moisture content using dryer $\left(20-25^{\circ} \mathrm{C}\right)$ and the final moisture content is $13 \%$.

- $\quad$ Milling: For milling, a mortar and pestle were used to remove husks (Figure 1).

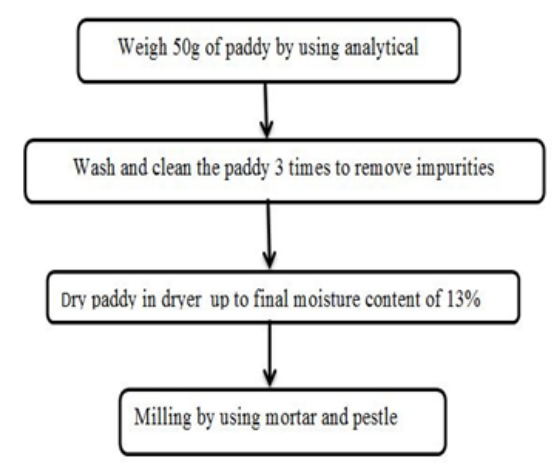

Figure 1: The method used for non-parboiled rice.

The preparation steps as applied for non-parboiled rice.

\section{Physico Chemical Analysis}

\section{Determination of total ash}

The method used during ash determination was the dry ashing method from (Prof LE Wongo, 2005) the material that was required was: Muffle furnace, Desiccator, and Crucible. The procedure used wasto take $5 \mathrm{~g}$ of fresh sample for the determination, transfer it into a muffle furnace maintained at $550-600^{\circ} \mathrm{C}$ for 3 hours. Cool in a desiccator and weigh. The measurement required was the weight of empty crucible, crucible with ash, and crucible with sample for 
test and the calculation was Total ash on dry basis percent $=((\mathrm{W} 2$ $-\mathrm{W})) /((\mathrm{W} 1-\mathrm{W})) \times 100$

Where, W2 = Weight in g of crucible with the ash,

$\mathrm{W}=$ Weight in $\mathrm{g}$ of empty crucible,

W1 = Weight in $\mathrm{g}$ of crucible with the dried material taken for test.

For the entire procedure, see Appendix 5.

\section{Determination of crude fat}

The method used for fat determination was from (Prof LE Wongo, 2005), the $5 \mathrm{~g}$ sample was weighed and wrapped up in a filter paper/thimble paper and place in the extraction thimble and transferred in Soxhlet about $250 \mathrm{ml}$ petroleum ether were used and taken on the heating mantle and switched on, the sample was heated for about $3 \mathrm{~h}$, the solvent were evaporated by using rotating evaporator finally the flask wascooled. The weight of flask before extraction and after extraction is recorded. Then the fat content will be calculated as follows:

The $\%$ fat content $=((X-Y) \times 100) / Z$

Where; $\mathrm{X}=$ weight of fat + flask,

$\mathrm{Y}=$ weight of flask,

$\mathrm{Z}=$ weight of sample.

For the entire procedure, see Appendix 3.

\section{Determination of crude protein}

Crude protein determination was done in 3 steps which were digestion, distillation and titration, during digestion $1 \mathrm{~g}$ of sample, $3 \mathrm{~g}$ of catalyst and $10 \mathrm{ml}$ of H2SO4and then heated for 4 hours till the sample turned to green color, after the sample were cooled, 100 $\mathrm{ml}$ of distilled water were added, the second step were distillation where we used a distiller. We used 10 mlof sample, $10 \mathrm{ml}$ of $\mathrm{NaOH}$ of $15 \%$ in distillation tube, and $5 \mathrm{ml}$ of boric acid in conical flask and distilled for 15 minutes. After distillation we did titration using $\mathrm{H} 2 \mathrm{SO} 4$ of $0.01 \mathrm{~N}$ in graduate burette and the sample from distillation (distillate)were titrated andthe initial and final volume were recorded calculations were as follow;

$\mathrm{N} \%=((\mathrm{ml}$ of acid for sample-ml of acid for blank $\times \mathrm{M}$ of acid used in titration $\times$ dilution factor $\times 14 \times 100) /($ weight of sample in $\mathrm{mg}$ )

Crude protein $=\% \mathrm{~N} \mathrm{X} \mathrm{FM}$

FM= multiplication factor (5.95).

For the entire procedure, see Appendix 4.

\section{Thiamin (vitamin b1) analysis}

Vitamin B1 was analyzed by using Thiochrome Fluorometric Procedure (AOAC Method 942.23) where autoclave, incubator, column chromatograph, $\mathrm{pH}$ meter, centrifuge, spectro photometer were used, the $3 \mathrm{~g}$ of sample were weigh and $65 \mathrm{ml}$ of $\mathrm{HCl}$ with $0.1 \mathrm{~N}$ were added and then autoclaved at $121^{\circ} \mathrm{C}$ for $30 \mathrm{~min}$ (sterilization) and after sterilization CH3COONa.3H2O were used to increase Ph to 5 and add enzyme solution of yeast used in baking which was diluted by taking $3 \mathrm{~g}$ in $100 \mathrm{ml}$ of heated distilled water (act as Amylase) and after they were incubated at 470C for 3 hours, after the Ph were also adjusted to 3 by $\mathrm{HCl}$ of $1 \mathrm{~N}$ the samples were filtered and passed into column chromatograph after the table here below was used for test in centrifugation and decantation and in spectrophotometer reading at different wavelength $(365 \mathrm{~nm}$ and $425 \mathrm{~nm})$. Table 2 below shows the used formula during Thiamine analysis (Table 2).

Table 2: The used formula during Thiamine analysis.

\begin{tabular}{|c|c|c|c|c|}
\hline Tube No. & Std & Bl-Std & $\mathbf{S}$ & Bl-S \\
\hline $\mathrm{KCl}$ or $\mathrm{NaCl}(\mathrm{g})$ & 1.5 & 1.5 & 1.5 & 1.5 \\
\hline Sample solution (ml) & - & - & 5 & 5 \\
\hline Std. Solution conc. $0.2 \mathrm{ug} / \mathrm{ml}(\mathrm{ml})$ & 3 & 3 & - & - \\
\hline Oxidizing reagent $(\mathrm{ml})$ & 3 & - & 3 & - \\
\hline $15 \% \mathrm{NaOH}$ & - & 3 & - & 3 \\
\hline & \multicolumn{4}{|c|}{ Swirl the tubes } \\
\hline \multirow[t]{4}{*}{ Isobutanol (ml) } & 13 & 13 & 13 & 13 \\
\hline & \multicolumn{4}{|c|}{ After adding each tube shake vigorously at least $15 \mathrm{sec}$} \\
\hline & \multicolumn{4}{|c|}{ After adding all tubes, shake. 2 min } \\
\hline & \multicolumn{4}{|c|}{ Centrifuge at low speed } \\
\hline Pipette or decant isobutyl alcohol to Measure fluorescence & S & SB & $\mathrm{U}$ & UB \\
\hline
\end{tabular}

Formula used were

Thiamin (mg per $100 \mathrm{~g}$ sample) $=((\mathrm{U}-\mathrm{UB})) /((\mathrm{S}-\mathrm{SB})) \times \mathrm{C} /$ $\mathrm{A} \times 25 / \mathrm{V} \times 100 / \mathrm{Wt} \times 100 / 1000$

$\mathrm{U}=$ fluorescence reading of sample (tube S)
$\mathrm{UB}=$ fluorescence reading of sample blank (tube Bl-S)

$\mathrm{S}=$ fluorescence reading of standard (tube Std)

$\mathrm{SB}=$ fluorescence reading of sample (tube Bl-Std) 


\author{
$\mathrm{C}=$ concentration of the standard $(\mu \mathrm{g})$ \\ $\mathrm{A}=$ test solution taken $(\mathrm{mL})$ \\ 25 = final volume of elute $(\mathrm{mL})$ \\ $\mathrm{V}=$ volume used in purification step $(\mathrm{mL})$ \\ $100=$ volume of original sample was made up to $(\mathrm{mL})$ \\ Wt. = sample weight $(\mathrm{g})$.
}

For the entire procedure, see Appendix 6.

\section{Sensory Evaluation}

Sensory evaluation refers to the study of the product quality characteristics by using human sensory organs. In the present study, the sensory activity was conducted in the processing laboratory of UR-CAVM, Busogo campus. The rice paddy was cooked in rice cooker where 1.5:5 ratios of paddy and water for each variety were used. During analysis, aquestionnaire with 9 hedonic scales was developed. Thirty (30) panelists(final year student of UR-CAVM, Busogo campus) were trained about sensory activity and requirements and were used for ranking of all 9 samples of cooked rice; the sensory attributes were color, taste, texture, flavor and odor. The panelists were served with safe and potable water to rinse their mouth before and after tasting each sample. They were served with papers to write marks and any comment for each evaluated sample.

\section{Statistical Analysis}

The statistical analysis in the present study was done to analyze the result after sensory and proximate analysis, Microsoft excel and SPSS of coding and the presentation of data through tabulation have been done; in SPSS, the means plot and comparison of mean have been used and Analysis Of variance (ANOVA) have been used during interpretation and discussion on the result.

For the ANOVA Table, see Appendix 2.

\section{Results and Discussion}

\section{Approximate analysis}

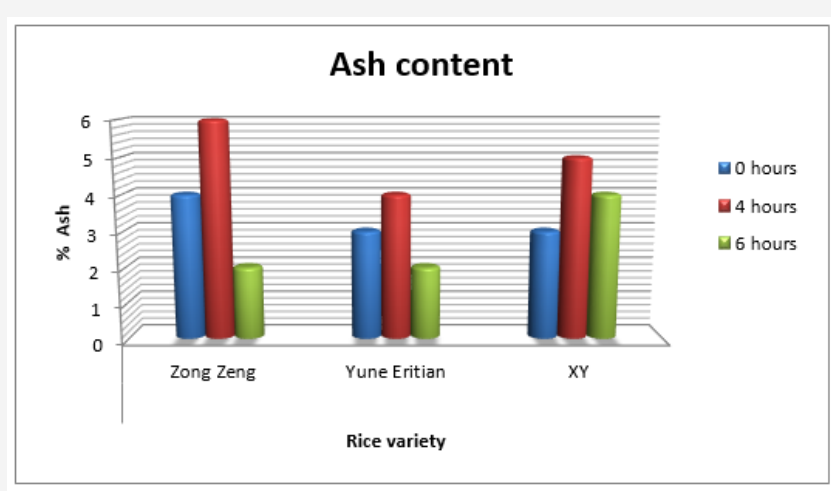

Figure 2: Ash content of raw rice (0 hour) and parboiled rice (soaked for 4 and 6 hours).

Ash content: Ash content refers to the measurement of the total amount of minerals present inconsumable and/or non-consumable material. Based on data obtained by use of ANOVA table, there is no significant difference for the ash content in the parboiled and non-parboiled rice of Zong zeng, Yune Eritian and XY rice varieties as the p-value was 0.1920 .534 and 0.214 at $\alpha=0.05$ respectively. and However, soaking for 4 hours showed more ash content of 6, 4 and $5 \%$ compare to non-soaked of 4,3 and $3 \%$ while the soaking of the same variety for 6 hours resulted in 2, 2 and 4 for Zong Zeng, Yune Eritian and $\mathrm{XY}$ varieties respectively of ash content. The results of ash content obtained during analysis are shown in (Figure 2). Comparing all 3 varieties, soaking for 4 hours showed more ash content compared to the one not soaked soaking for 6 hours. However, XY variety is richer in ash compared to Zong zeng and Yune Eritian.

Protein content: Protein in parboiled and non-parboiled rice was determined by using of Kedjhald method. Based on data obtained by using ANOVA Table, there is no significant difference for Protein content in parboiled and non-parboiled rice of Zong zeng, Yune Eritian, and XY as the p- value was $0.124,0.507$ and 0.542 at $\alpha=0.05$ respectively. and However, soaking for 4 hours showed protein content of $5.29 \%, 5.08 \%$, and $4.49 \%$, for non-soaked show protein content of $4.42 \%, 4.08 \%$ and $6,58 \%$ while the soaking of the same variety for 6 hours resulted in 5.58\%, 5,91\%and $6.49 \%$ for Zong Zeng, Yune Eritian and XY varieties respectively of protein content (Figure 3). For protein and fat content change occur mainly after germination it was probably suggest by [15] that there is biosynthesis of new compound during germination.

Fat content: The fat content in 3 rice varieties were determined using Soxhlet method where fat was extracted using Petroleum ether. Based on the data obtained by using ANOVA Table, there is significant difference for Fat content in parboiled and nonparboiled rice of Zong zeng, Yune Eritian, and XY as the p-value was $0.000102,0.00012$ and 0.00018 at $\alpha=0.05$ respectively. and soaking 
for 4 hours showed Fat content of 5.94\%, 5.96\%, and 7.91\%, for non-soaked show Fat content of $3.95 \%$, 3.95\% and 3.95\% while the soaking of the same variety for 6 hours resulted in $3.98 \%$ 3.96\%and $5.96 \%$ for Zong Zeng, Yune Eritian and XY varieties respectively of Fat content (Figure 4).

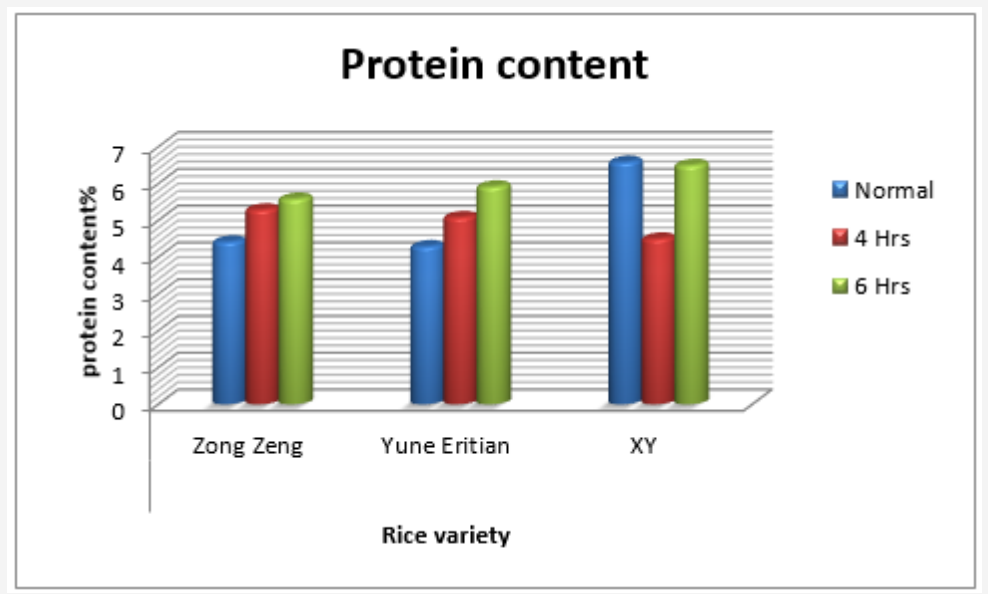

Figure 3: Protein content of parboiled rice soaked 6hours and 4 hours and non-parboiled rice. The protein content obtained after analysis for the 3 used varieties.

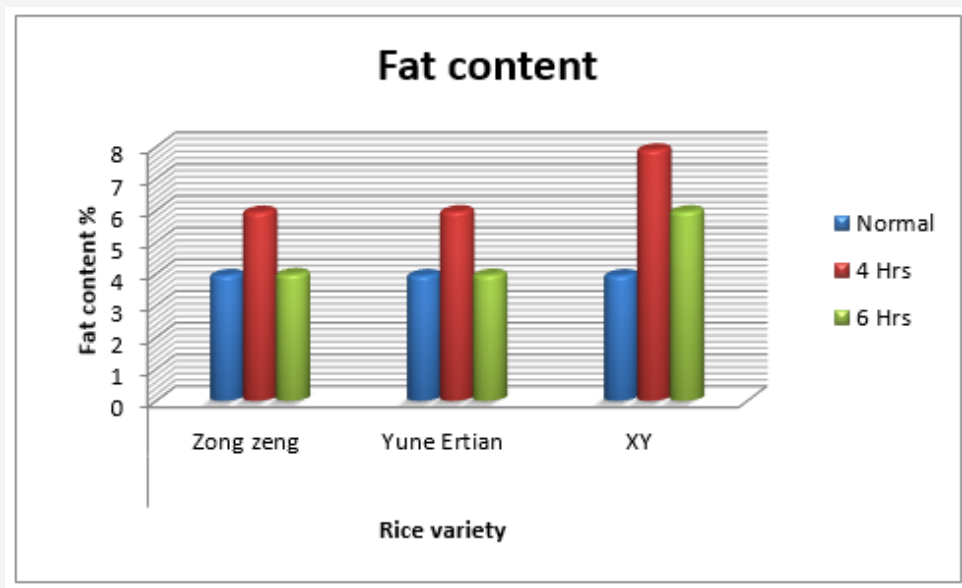

Figure 4: Fat content of parboiled soaked 6 hours and 4 hours and non-parboiled rice.

The fat content obtained after analysis for the 3 used varieties.

Comparing the soaking period which have been soaked for 4 hours has more fat content compare to soaked 6 hours and the one not soaked, according to variety XY has more fat content compare to Yune Eritian and Zong zeng variety. Regarding lipid content, a significant difference $(p<0.05)$ was observed between parboiled and non-parboiled rice samples, parboiled rice has high fat content due to leaching and rupture of oil globule that occur due to increase in temperature and steaming pressure that occur during parboiling process (Ogbonnaya Chukwu, 2009)

Vitamin B1 content: Based on the data obtained by using ANOVA Table, there is significant difference for Fat content in parboiled and non-parboiled rice of Zong zeng, Yune Eritian, and XY as the pvalue was $0.005,0.011$ and 0.001 at $\alpha=0.05$ respectively. and soaking for 4 hours showed vitamin B1 content of $0.092032 \mathrm{mg} / 100 \mathrm{~g}$ of sample, $0.025519 \mathrm{mg} / 100 \mathrm{~g}$ of sample and $0.033674 \mathrm{mg} / 100 \mathrm{~g}$ of sample for non-soaked show Vitamin B1 content of 0.089893 $\mathrm{mg} / 100 \mathrm{~g}$ of sample, $0.024767 \mathrm{mg} / 100 \mathrm{~g}$ of sample and 0.149894 $\mathrm{mg} / 100 \mathrm{~g}$ of sample while the soaking of the same variety for 6 hours resulted in $0.667817 \mathrm{mg} / 100 \mathrm{~g}$ of sample, $0.135146 \mathrm{mg} / 100 \mathrm{~g}$ of sample and $0.341531 \mathrm{mg} / 100 \mathrm{~g}$ of sample for Zong Zeng, Yune Eritian and XY varieties respectively of VitaminB1 content. Below figure indicate vitamin B1 content present in Zong zeng, Yune Eritian and XY (Figure 5).

According to the obtained data Zong zeng varieties has high amount of Thiamin compare to XY and Yune Eritian, depending on the soaking time, the one soaked for $6 \mathrm{~h}$ has more thiamine compare to normal and soaked for 4 hours. For vitamin B1 Thiamine there increase in content for parboiled rice this agreed with finding of (BO Otegbayo, 2001) who have study on the effect of parboiling on physicochemical qualities of the two local rice varieties in Nigeria 
that it was due to the fact that during steaming, water soluble vitamins are spreaded throughout the grain, thus altering their distribution and concentration with inflision of thiamine from the germ into starch endosperm.

\section{Sensory analysis}

Color acceptability: Color is the quality of an object or substance with respect to the light- reflect by the object and its determined vision during sensory evaluation panelist were supposed to indicate their level of acceptability on the color of parboiled and non-parboiled rice. Based on the data obtained by using ANOVA Table, there is no significant difference for color acceptability in parboiled and non-parboiled rice of Zong zeng, Yune Eritian, and XY as the p- value was $0.30,0.37$ and 0.09 at $\alpha=0.05$ respectively. However, soaking for 4 hours the color acceptability was $5.9,6.33$ and $6.13 \%$ for non-soaked show color acceptability of $6.46,6.90 \%$ and $6.73 \%$ while the soaking of the same variety for 6 hours resulted in 5.80\%,6.46\%, 5.76\% for Zong Zeng, Yune Eritian and $\mathrm{XY}$ varieties respectively of color acceptability (Figure 6).

According to the color acceptability parboiled rice has not get high means score compare to the non- parboiled rice so the change in color was due to the steaming temperature and period according to and researcher has found that the discoloration was mainly caused by non-enzymatic browning reaction (Maillard reaction)
(George, 2012). The color the change of color to brown was due to the soaking temperature and time used to soak it as according to [16] the lower soaking temperature provide less colored product, the whiteness and lightness of parboiled rice was affected by temperature and time of steaming they have found that that color can cause the negative effect on the marked, so they have found that the discoloration is caused by Maillard type of non-enzymatic browning and the processing condition which determine the intensity of color during parboiling and even the husk pigment also can contribute to the intensity of color during diffusing into endosperm during soaking.

\section{Flavor acceptability}

Flavor refers to the quality of something that affect the sense of taste and smell sensation are evoked by substance in mouth panelist were supposed to sensor the flavor of both parboiled and non-parboiled rice. Based on the data obtained by using ANOVA Table, there is no significant difference for Flavor acceptability in parboiled and non-parboiled rice of Zong zeng, Yune Eritian, and XY as the $p$ - value was $0.759,0.870$ and 0.870 at $\alpha=0.05$ respectively. However, soaking for 4 hours showed flavor acceptability of 6.200 , 6.733 , and $6.100 \%$ for non-soaked show6.466, 6.933, and 6.133 while the soaking of the same variety for 6 hours resulted in 6.233 , 6.566, 6.333 for Zong Zeng, Yune Eritian and XY varieties respectively of flavor acceptability (Figure 7).

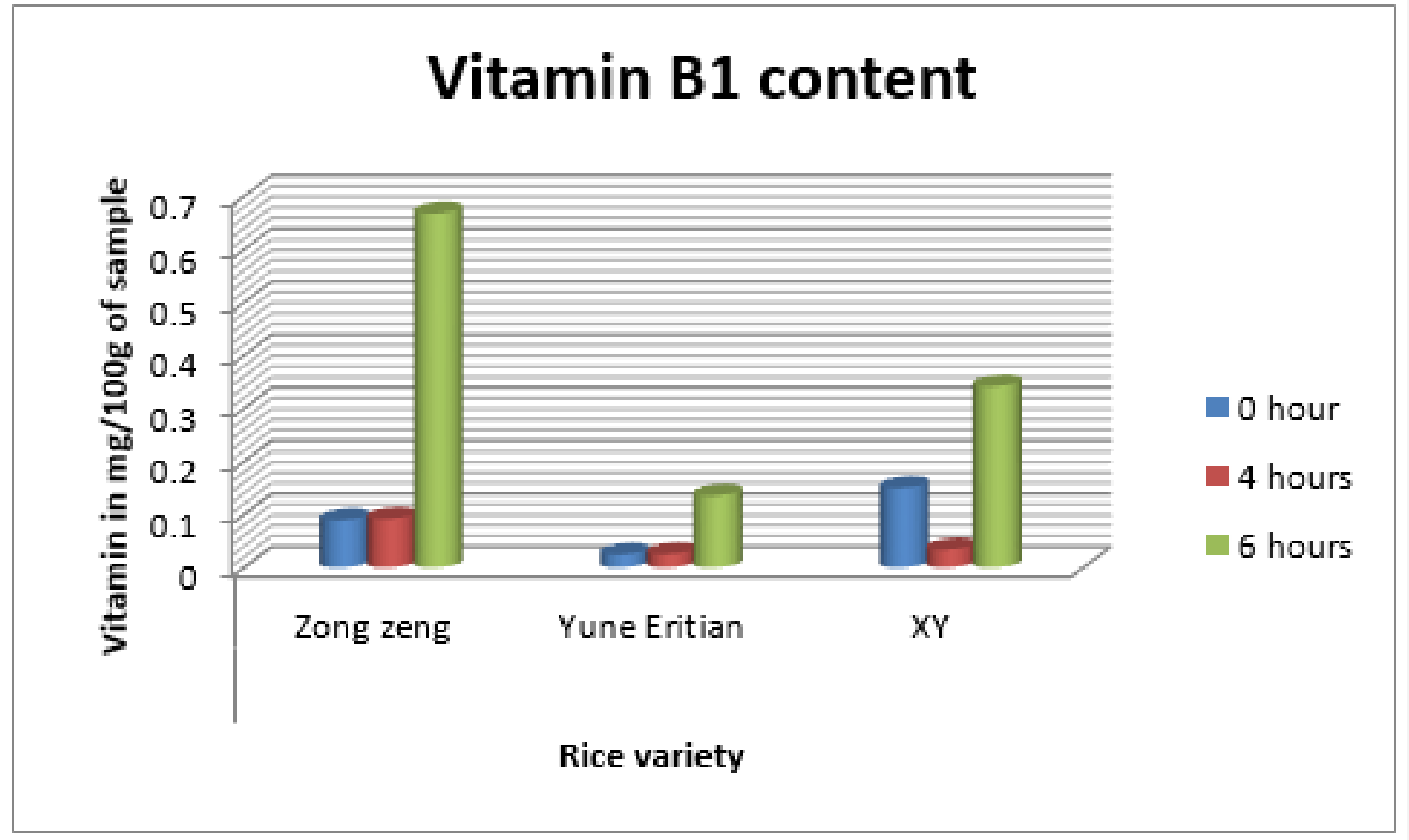

Figure 5: Vitamin B1 (Thiamin) of parboiled rice soaked 6hours and 4 hours and non-parboiled rice. vitamin B1 content present in Zong zeng, Yune Eritian and XY. 


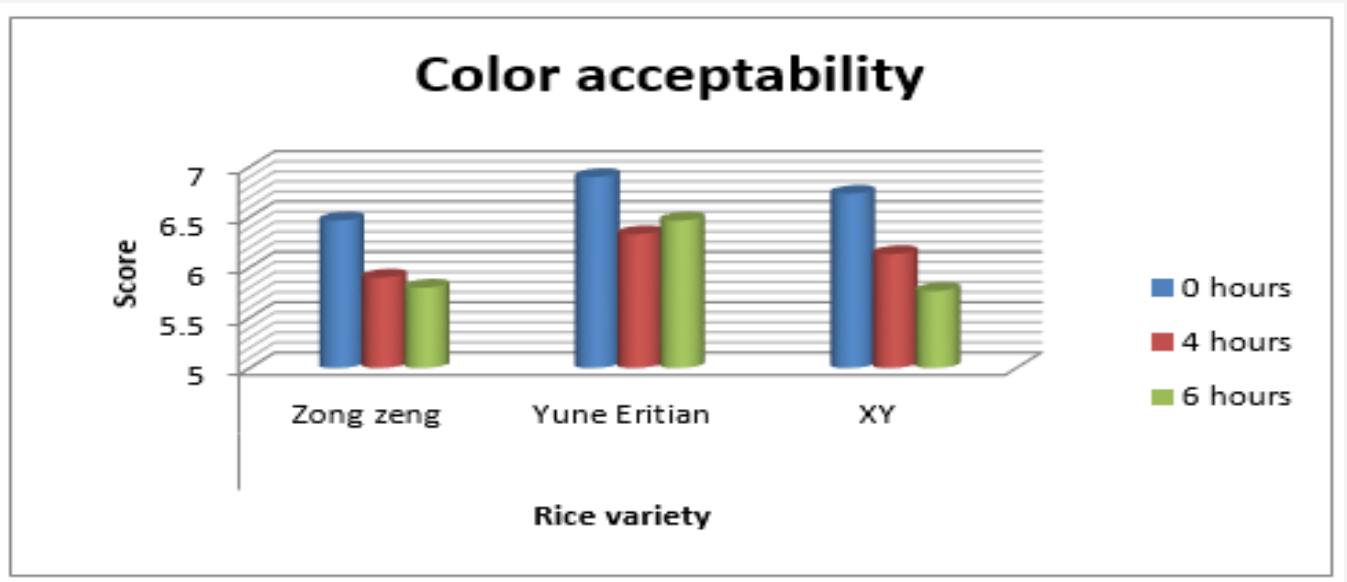

Figure 6: Color acceptability of parboiled soaked 6 hours and 4 hours and non-parboiled rice.

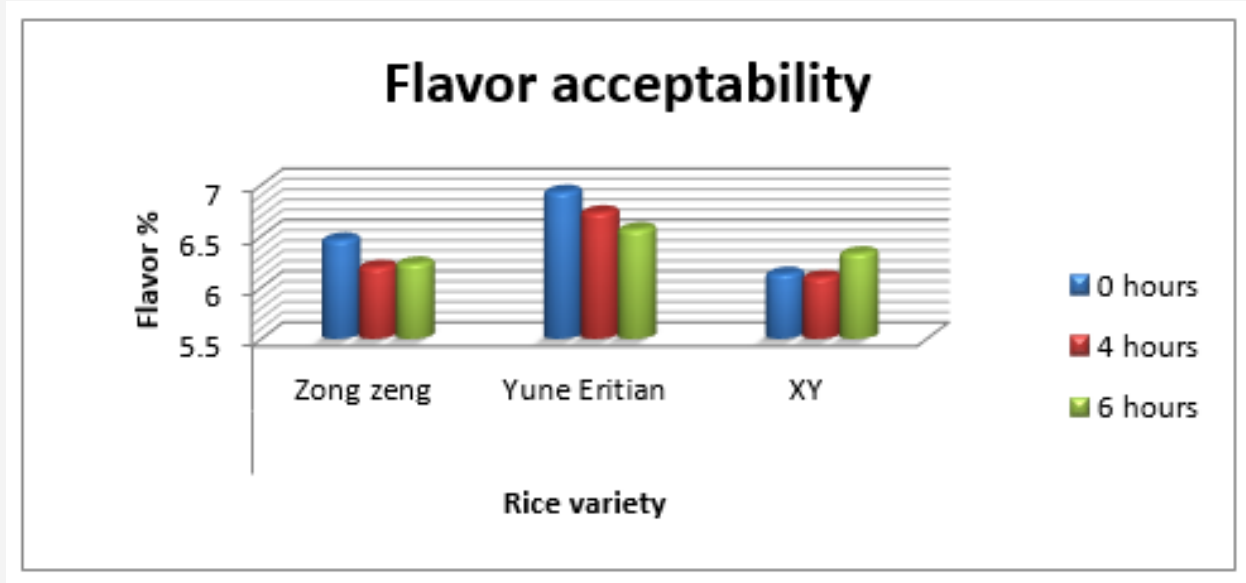

Figure 7: Flavor acceptability of parboiled rice soaked 6 hours and 4 hours and non- parboiled rice.

According to the data Yune Eritian have been more acceptable flavor acceptable compare to Zong zeng and XY and comparing according the soaking time the rice not soaked has more flavour acceptability compare to the rice soaked 6 hours and rice soaked 4 hours.

Odor acceptability: Odor is sensation resulting from adequate stimulation of the olfactory organ (nose) during sensory analysis the panelist was required to analyze the odor of the parboiled and non-parboiled rice. Based on the data obtained by using ANOVA Table, there is no significant difference for odor acceptability in parboiled and non-parboiled rice of Zong zeng, XY as the $\mathrm{p}$ - value was $0.142,0.455$ at $\alpha=0.05$ respectively. However, soaking for 4 hours showed 6.30 and $6.56 \%$ for non-soaked show odor acceptability of 6.63 , and $6.73 \%$ while the soaking of the same variety for 6 hours resulted in 5.90 and $6.23 \%$ for Zong zeng, and XY varieties respectively of odor acceptability.

Based on the results obtained by use of ANOVA on the Yune Eritian variety there is a significant difference between parboiled and non-parboiled rice as $P$-value is 0.01 at $\alpha=0.05$, according to the mean plot Yune Eritian not parboiled has higher odor acceptability of $7.2 \%$ than parboiled soaked 6hours with odor acceptability of $6.2 \%$ and 4 hours with odor acceptability of $6.1 \%$ (Figure 8).

Comparing the variety Yune Eritian has more odor acceptability compare to XY and Zong zeng comparing to the soaking time the rice which have been not parboiled has been more odor acceptable compare to the rice soaked for 4 hours and 6 hours.

Texture acceptability: Texture refers to the appearance, feeling, or consistency of surface or substance, panelists is supposed to analyze the texture of both parboiled and non-parboiled rice. Based on the data obtained by using ANOVA Table, there is significant difference for texture acceptability in parboiled and non-parboiled rice of Yune Eritian, XY as the p- value was $0.014,0.01$ at $\alpha=0.05$ respectively.The soaking for 4 hours showed 5.966 and $6.20 \%$ for non-soaked show texture acceptability of 5.966 and $5.233 \%$ while the soaking of the same variety for 6 hours resulted in 7.033 and $6.733 \%$ for Yune Eritian and XY varieties respectively of Texture acceptability. Based on results obtained with ANOVA table, Zong zeng variety there is no significant difference between parboiled and non-parboiled rice as $\mathrm{p}$ - value is 0.332 at $\alpha=0.05$ whereas according to the mean Zong zeng not soaked has high texture acceptability 
at level of $6.466 \%$ compare to Zong zeng soaked 4 hours with level of acceptability of $5.966 \%$ and Zong zeng soaked for 6 hours. (Figure 9) below chat indicates the level of acceptability of flavor to all varieties.

Comparing to the variety Yune Eritian compare to Zong zeng and $\mathrm{XY}$ varieties, by comparing the time of soaking the rice par- boiled and soaked for 6 hours compare to rice soaked for 4 hours and not soaked. According to the texture for the parboiled rice is hard compare to non-parboiled rice then according to [16] that hardness was due to the moisture content after drying, balance of starch, gelatinization and retro gradation which occur during parboiling.

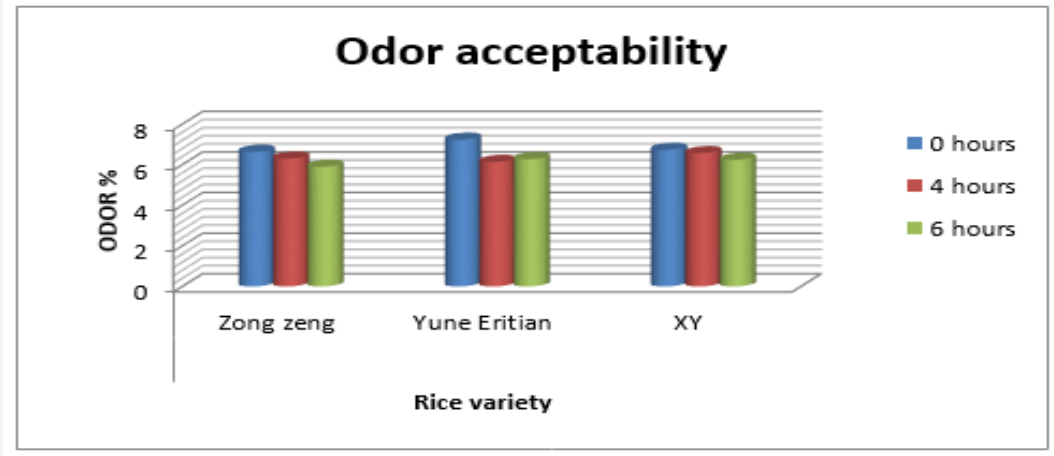

Figure 8: Odor acceptability of parboiled rice soaked 6 hours and 4 hours and non-parboiled rice.

The level of odor acceptability of parboiled rice and non-parboiled one.

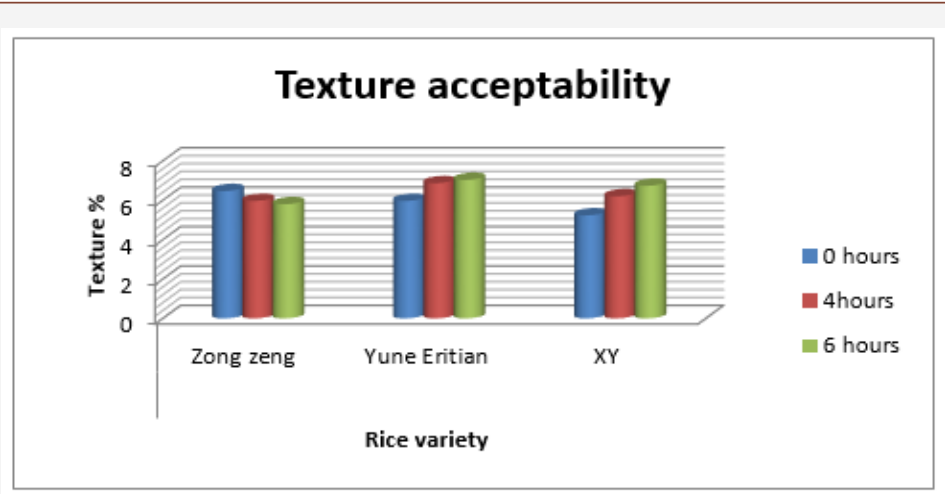

Figure 9: Texture acceptability of parboiled rice soaked 6 hours and 4 hours and non-parboiled.

The level of acceptability of flavor to all varieties.

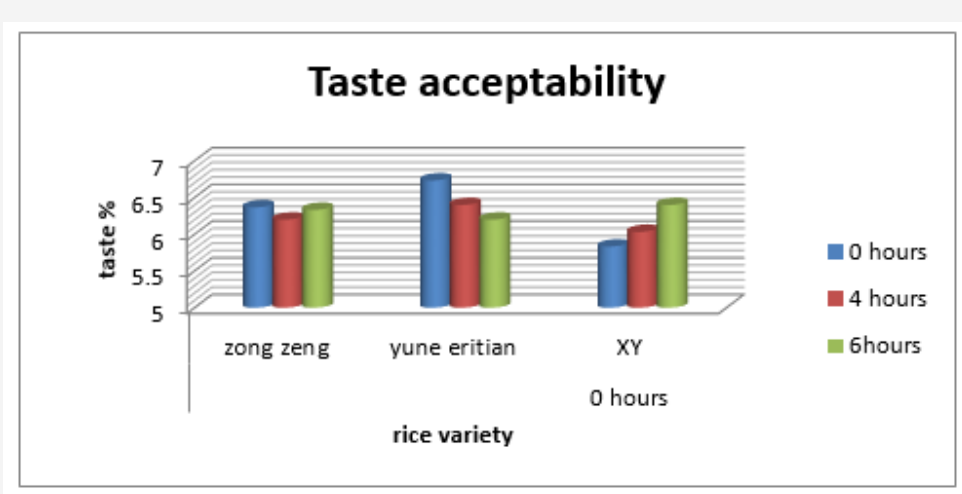

Figure 10: Taste acceptability of parboiled rice soaked 6 hours and 4 hours and non- parboiled rice.

Taste acceptability: Based on the data obtained by using ANOVA Table, there is no significant difference for Taste acceptability in parboiled and non-parboiled rice of Zong zeng and Yune Eritianas the $p$ - value was $0.095,0.442$ at $\alpha=0.05$ respectively. However, for rice soaked for 4 hours, the taste of acceptability was 6.2 and $6.4 \%$. For, non-soaked, the taste acceptability was 6.633 and $6.733 \%$ while soaking of the same variety for 6 hours resulted in 6.333 and $6.200 \%$ for Zong Zeng and Yune Eritian varieties respectively. For 
XY variety based on the results obtained through the ANOVA table, there is a significant difference between parboiled and non- parboiled rice as P-value is 0.0475 at $\alpha=0.05$. According to the mean plot the taste of parboiled 6 hours $6.400 \%$ was accepted than 4hours $6.033 \%$ and the non-parboiled $5.833 \%$. The (Figure 10 ) below indicates the taste acceptability of non-parboiled and parboiled rice.

Comparing to variety Yune Eritian has high taste acceptability compare to Zong zeng and XY variety. Poor taste acceptability of parboiled rice was due to poor non gelatinized of the endosperm starch as some biochemical change that could transform or inactivate certain pigment and enzyme enabling taste in parboiled rice to be evoke did not occur [17].

\section{Conclusion}

As the research has demonstrated, it is clear that parboiling technology of rice minimizes the postharvest losses by reducing rice breakability compared to non-parboiled rice. As far as the nutritional content is concerned parboiled rice varieties were found to be more nutritious, and the nutritional content of parboiled rice differed according to their varieties. But when it came to consumer acceptability it was a different case because non-parboiled rice was more acceptable than the parboiled one, we assume that the reason to why parboiled rice varieties had a poor general acceptability than non-parboiled one is because parboiled rice had a smell of the autoclave due to the steaming effect, and unfortunately that smell is not suitable to human olfactory organ which is why we presume that it should be the reason of that poor acceptability. As far as the nutritional content among varieties is concerned, we found that long variety (XY) were more nutritious than short varieties (Yune Eritian, Zong Zeng) whereas among all the varieties Yune Eritian was more acceptable to consumers than the rest.

\section{Recommendations}

According to the results from the research we recommend the following;

- Other researchers: they should work on other parameters such as carbohydrates and fibers to identify portions of nutritional content of rice, they can as well change the soaking temperature and steaming period(time) of parboiling

- Rwandan society: since parboiled rice is more nutritive than non-parboiled rice we recommend Rwandese to consume it. And we would encourage extensional workers for awareness of such technic among different stakeholders and beneficiaries as well as rice processors to adopt this technic.

\section{Acknowledgement}

The research was technically supported by Rwanda Agriculture and Animal Resources Development Board (RAB) and University of Rwanda (UR).

\section{Conflict of Interest}

No conflict of interest.

\section{References}

1. Lidia Dandedjrohoun, Aliou Diagne, Gauthier Biaou, Simon N'Cho, Soul-Kifouly Midingoyi (2012) Determinants of diffusion and adoption of improved technology for rice parboiling in Benin. Revue d'Etudes en Agriculture et Environnement - Review of agricultural and environmental studies, INRA Editions 93(2): 171-191.

2. S Faria, P Bassinello, M Penteado (2012) Nutritional composition of rice bran submitted to different stabilization procedures. Brazilian Journal of Pharmaceutical Science 48(4): 651.

3. A Abbas, S Murtaza, F Aslam, A Khawar, S Rafique, et al. (2011) Effect of processing on Nutritional Value of Rice (Oryza sativa). World Journal of Medical Sciences 6(2): 68-73.

4. Grist DH (1955) Rice. Bristol, London.

5. J Dirck (2010) Developing competitive rice value chains. Associates for International Resources and Development, Arlington, Massachusetts, USA, 3: 1-5.

6. Muhammad Pervez Wasim (2002) Astudy of rice in the major growing countries of the world, their growth instability and world share. Pakistan economy and social review. 40(2): 153-183.

7. CK Probart, PJ Bird, KA Parker (1993) Diet and Athletic Performance. Medicine and Clinical Journal of North America 5: 77- 757.

8. PR Jennings, WR Coffman, HE Kauffman (1979) Rice Improvement, International Rice Research Institute, Los Banos, Philippines, p.186.

9. M Frei, K Becker (2003) Studies on the in vitro starch digestibility and glycemic index of six different indigenous rice cultivars from the Philippines. Journal of Food Chemistry 83: 395-400.

10. (2006) Food and Agriculture Organization/ International Rice Research Institute, FAO Food and Nutrition Series, FAO Rome, p.26.

11. Samuel A Matz (1991) Rice Cereal as food feed by Samuel A Matz (ed). SK Jain for CBS Publisher and distributor, New Delhi, India, pp. 215-256.

12. Minagri (2009) Ministry of Agriculture and Animal Resources national rice programme Report.

13. Matty Demont, Espérance Zossou, Pieter Rutsaert, MaimounaNdoura, PaulVan Mele, et al. (2012) Consumer Valuation of Improved Rice Parboiling Technologies in Benin. Food Quality and Preference 23 (1): 63-70.

14. Rao RSN, SO Juliano (1970) Effect of Parboiling on Some PhysicoChemical Properties of Rice. J Agric Food Chem 18(2): 289-294.

15. SA Tiamiyu, A Usman, UB Ugalahi (2014) Adoption of on-farm and postharvest rice. Quality Enhancing Technologies 32(2): 67-72.

16. K Sareepuang, S Siriamornpun, L Wiset, N Meeso (2008) Effect of Soaking Temperature on Physical, Chemical and Cooking Properties of Parboiled Fragrant Rice. World Journal of Agricultural Sciences 4(4): 409-415.

17. AJ Ayamdoo, B Demuyakor, FK Saalia, Addy Francis (2014) Effect of varying parboiling condition on the cooking and eating/ sensory characteristics of Jasmine 85 and Nerica 14 rice varieties. American journal of food technology 9(1): 1-14. 